\title{
Lesen bildet.
}

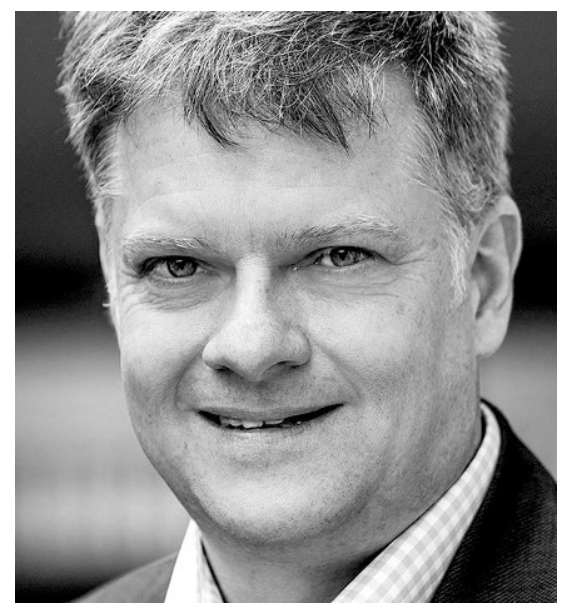

Monat für Monat leuchten die Autoren der DuD aktuelle Themen und Fragestellungen des Datenschutzes und der Informationssicherheit aus. Meist geht es dabei um sehr spezifische Fragestellungen oder Lösungsansätze, die das Zusammenspiel von Recht und Technik oder Grenzen und Interaktionen mit "benachbarten“ Rechtsbereichen betreffen und im Detail diskutiert werden.

Hinter jeder dieser Vertiefungen steht natürlich das "große Ganze“, der Datenschutz als ein Grundrecht und die Informationssicherheit zum Schutz von Daten und IT-Infrastrukturen, von denen inzwischen das Funktionieren unserer Gesellschaft in wachsendem Umfang und in immer weiteren Bereichen abhängig ist. Welches Ausmaß diese Abhängigkeit bereits angenommen hat, zeigt uns gerade die Corona-Pandemie: Trotz drastischer Reduktion zwischenmenschlicher Kontakte können wir unser Zusammenleben und - wirtschaften offenbar zu großen Teilen und zumindest über eine begrenzte Zeit mit Hilfe der Informationstechnik aufrechterhalten.

Die Diskussionen um technische Lösungen zur Kontaktrückverfolgung oder die Implikationen des Einsatzes von Videokonferenzsystemen haben aber auch gezeigt, dass das derzeitige "Mehr" an Informationstechnik auch seinen Preis hat. Um zu verhindern, dass vor lauter Bäumen der Wald aus dem Blick gerät, lohnt es gelegentlich, einen Schritt zurück zu treten und erneut das "große Ganze" des Datenschutzes und der Informationssicherheit zu betrachten. Vielleicht gilt das sogar ganz besonders jetzt.

Viele spätere technische und gesellschaftliche Entwicklungen sind in den vergangenen rund 150 Jahren von Schriftstellern lange zuvor erahnt und beschrieben worden. Einige davon haben sich als treffende Voraussagen erwiesen und manchmal auch den gesellschaftlichen Diskurs der möglichen Folgen nachhaltig geprägt. Das ist nicht verwunderlich, bekommen doch die theoretischen Möglichkeiten erst durch eine realistische Erzählung Gestalt, werden dadurch vorstellbar und greifbar. Wenn es einem Autor dabei gelingt, in seiner Geschichte - meist einer Dystopie - die zentralen Fragen aufzuwerfen und in ihrer Bedeutung erkennbar zu machen, kann eine solche Erzählung mehr Grundverständnis vermitteln als hunderte theoretische Betrachtungen. Das gilt vielleicht sogar ganz besonders für den Datenschutz und die Informationssicherheit, da sich beide Themenbereiche in erster Linie mit abstrakten Bedrohungen beschäftigen, die sich erst in einzelnen Vorfällen konkretisieren - auf deren Vermeidung unser aller Engagement ja zugleich gerade zielt. Ein Dilemma: Je erfolgreicher der Schutz, desto abstrakter und unkonkreter die Gefahr.

Aus einer Diskussion mit Datenschutz- und Datensicherheitsexperten in Süddeutschland entstand daher kürzlich die folgende, zweifellos nicht vollständige Liste von zehn belletristischen Werken, die die Bedeutung von Datenschutz und Datensicherheit in besonders beeindruckender Weise konkret werden lassen (geordnet nach Erscheinungsjahr):

1. George Orwell: 1984 (1948)

2. Clifford Stoll: Das Kuckucksei / Cuckoo's Egg (1989)

3. Robert Harris: Enigma (1995)

4. John Katzenbach: Der Patient (2006)

5. Jeffery Deaver: Der Täuscher (2009)

6. Marc Elsberg: Blackout (2012)

7. Dave Eggers: Der Circle (2013)

8. Marc Elsberg: ZERO (2014)

9. Marc-Uwe Kling: Quality Land (2017)

10. Andreas Eschbach: NSA (2018)

Einige werden Ihnen zweifellos bekannt sein. Alle anderen empfehle ich Ihnen wärmstens zur Lektüre. Und wenn Sie das nächste Mal gefragt werden, warum Datenschutz oder Datensicherheit bloß so wichtig genommen werden und Sie nicht zu einer profunden Antwort ausholen möchten, empfehlen Sie einfach - ein Buch.

Dirk Fox 